\title{
O trabalho como princípio educativo na perspectiva da Educação Profissional e
}

\section{Tecnológica}

\author{
Work as an educational principle from the perspective of Professional and Technological Education \\ El trabajo como principio educativo desde la perspectiva de la Educación Profesional y Tecnológica
}

\section{Resumo}

Este artigo tem como objetivo discutir o trabalho como princípio educativo na perspectiva da Educação Profissional e Tecnológica. Trata-se de uma abordagem sobre a evolução da identidade educativa do trabalho diante do sentido mercadológico adquirido historicamente através do processo de desenvolvimento capitalista, assim como sobre a educação e suas transformações ao longo da história, analisando suas mudanças e destacando o desvelamento quanto ao projeto educacional brasileiro atual. Este trabalho trata-se de uma pesquisa qualitativa, mediante estudo descritivo e bibliográfico, fundamentado em teóricos que estudam o assunto, dentre outros que contemplam a temática. Os resultados desta pesquisa revelam que é necessário entender as duas faces do trabalho, tanto no sentido ontológico, como no sentido histórico para compreender a totalidade da problemática da concepção de trabalho na educação profissional. $\mathrm{O}$ estudo conclui que é necessário considerarmos a dialética e as contradições imanentes ao desenvolvimento histórico da sociabilidade humana, apontando condições de possibilidade para a construção de um projeto de sociedade mais justo e humano, pensado para além do mercado, tendo como foco o trabalho como princípio educativo como concepção a ser adotada na Educação Profissional e Tecnológica.

Palavras-chave: Trabalho; Princípio educativo; Educação profissional e tecnológica.

\begin{abstract}
This article aims to discuss work as an educational principle from the perspective of Professional and Technological Education. This is an approach to the evolution of the educational identity of work in light of the marketing sense historically acquired through the process of capitalist development, as well as on education and its transformations throughout history, analyzing its changes and highlighting the unveiling of the project. current Brazilian educational This work is a qualitative research, through a descriptive and bibliographical study, based on theorists who study the subject, among others that contemplate the theme. The results of this research reveal that it is necessary to understand the two sides of work, both in the ontological and in the historical sense, for the entire problematic of the conception of work in professional education. The study concludes that it is necessary to consider dialectics and as contradictions
\end{abstract}


immanent to the historical development of human sociability, conditions of possibility for the construction of a more just and humane society project, thought beyond the market, as focusing on work as an educational principle as a concept to be adopted in Professional and Technological Education.

Keywords: Work; Educational principle; Professional and technological education.

\section{Resumen}

Este artículo tiene como objetivo discutir el trabajo como principio educativo desde la perspectiva de la Educación Profesional y Tecnológica. Es un acercamiento a la evolución de la identidad educativa del trabajo a la luz del sentido mercadológico históricamente adquirido a través del proceso de desarrollo capitalista, así como sobre la educación y sus transformaciones a lo largo de la historia, analizando sus cambios y destacando la develación del proyecto. actual educativa brasileña Este trabajo es una investigación cualitativa, mediante un estudio descriptivo y bibliográfico, basado en teóricos que estudian el tema, entre otros que contemplan el tema. Los resultados de esta investigación revelan que es necesario comprender las dos caras del trabajo, tanto en sentido ontológico como histórico, para toda la problemática de la concepción del trabajo en la educación profesional. El estudio concluye que es necesario considerar la dialéctica y como contradicciones inmanentes al desarrollo histórico de la sociabilidad humana, condiciones de posibilidad para la construcción de un proyecto de sociedad más justo y humano, pensado más allá del mercado, como focalización en el trabajo como principio educativo. como concepto a adoptar en la Educación Profesional y Tecnológica.

Palabras clave: Trabajo; Principio educativo; Educación profesional y tecnológica.

\section{Introdução}

O objeto de estudo desta pesquisa é o trabalho como princípio educativo na perspectiva da educação profissional e Tecnológica. Uma abordagem sobre a evolução da identidade educativa do trabalho diante do sentido mercadológico adquirido historicamente através do processo de desenvolvimento capitalista, assim como sobre a educação e suas transformações ao longo da história, analisando suas mudanças e destacando o desvelamento quanto ao projeto educacional brasileiro atual.

A reflexão sobre educação e trabalho é uma preocupação constante nos discursos educacionais, sendo uma questão justa, legítima e pertinente. Apesar disso, esta discussão tem sido, por vezes, apresentada de forma descontextualizada, ora superestimando a importância do trabalho em detrimento da educação, ora o inverso.

Isso pode ser compreendido como resultado de uma dualidade estrutural decorrente do sistema capitalista, que tem em seu seio a concepção de uma educação simples, mecânica e sem traços intelectuais para as classes menos favorecidas, reservando os postos de trabalhos mais simples e manuais.

Trazendo à luz a concepção de trabalho, alguns pensadores que estudam a categoria trabalho baseiam-se em Marx, para fundamentar seus argumentos. E é nesse pensador que se encontra uma definição do trabalho: "trabalho é um processo entre o homem e a Natureza, um processo em que o homem, por sua própria ação, media, regula e controla seu metabolismo com a Natureza" (Marx, 1983, p. 149).

Sendo assim, temos duas concepções claras de trabalho: uma no sentido ontológico, e outra no sentido mercadológico. A primeira, como defendida por Marx, está relacionada a esta interação com a natureza, com a transformação do ambiente ao redor para satisfação das demandas naturais do ser humano.

A segunda, no sentido mercadológico, que se aproxima da mediação de segunda ordem destacada por Mészáros (2008), está focada no mercado, no capital. É o trabalho no sentido do emprego, dividido de forma dual, dependendo de qual classe social o indivíduo pertence.

Vale destacar que as formulações acerca da historicidade do homem e de sua capacidade de superar histórica e socialmente as determinações materiais, invalidam as teses de que seus estudos são limitados à sociedade capitalista. A historicidade do sujeito social não pode sofrer uma redução a determinados espaços sociais historicamente estáticos, fixos, rígidos, como a compreensão exclusiva da sociedade capitalista (Augusto \& Carcanholo, 2014).

Assim compreendemos que não é um pensador limitado às análises do capitalismo, assim como também não é um teórico que não se limita exclusivamente à economia política. A teoria social inaugurada por Marx e, idealizada com base nas 
análises que fez dos diferentes modos de produção, confirma que os modos como o homem atua sobre a natureza, transformandoa para sua sobrevivência e perpetuação da espécie, são desenvolvidos de forma histórica e socialmente e, logo em seguida, ajustados, evoluídos e repassados para as gerações que se sucedem.

\section{Metodologia}

Esse estudo é de natureza qualitativa, entendida por Figueiredo (2009, p. 96) como uma pesquisa que surge diante da impossibilidade de compreender, através de dados numéricos, fenômenos ligados à intuição e subjetividade, portanto, não necessitando de uma estrutura numérica para analisá-lo, contudo, que produz uma enorme quantidade de dados narrativos. Assim, a nossa análise será feita a partir da investigação de dados encontrados nos documentos selecionados.

Como destacado por Minayo (2002) a abordagem qualitativa estabelece relações entre indivíduos e é proposta como "[...] tarefa central das ciências sociais a compreensão da realidade humana vivida socialmente" (Minayo, 2002, p. 23). O estudo apresentado teve como intenção, proporcionar aos educadores(as) entendimento e busca pela compreensão metodológica abarcados nesta proposta

Este trabalho é fruto da leitura crítica do referencial teórico previamente selecionado a partir de levantamento bibliográfico. De acordo com Gil (2008, p. 50), “a pesquisa bibliográfica é desenvolvida a partir de material já elaborado, constituído principalmente de livros e artigos científicos”.

Dessa forma, o objeto investigado será confrontado entre autores que tratam da temática em foco, o trabalho como princípio educativo, com o objetivo de compreendermos as proposições relacionadas às diferentes concepções que envolvem esta categoria marxista.

Nesse sentido, o presente artigo dialoga com autores que discutem numa perspectiva crítica a relação trabalhoeducação e seus sentidos ontológico e histórico/mercadológico.

\section{Resultados e Discussão}

Essa visão de EPT parte de uma concepção de ser humano como produtor da sua existência a partir de sua relação e atuação na natureza e com os outros seres humanos que definem o que é trabalho na perspectiva histórico-crítica.

O trabalho como princípio educativo faz parte das concepções trazidas nos conceitos do que chamamos de Currículo para o Ensino Médio Integrado à Educação Profissional (Ramos, 2011).

O currículo do Ensino Médio Integrado passou a ser pensado como um currículo que recomenda a dimensão de todos os saberes, de forma integrada ao conhecimento a ser recebido em sala de aula. Esse conhecimento, por sua vez, deveria ter como objetivo uma formação mais ampla, ou seja, integral do indivíduo (Ramos, 2011).

Nesse contexto, Pacheco (2012) afirma que alinham-se: (i) a formação humana integral; (ii) trabalho, ciência, tecnologia e cultura como categorias indissociáveis da formação humana; (iii) o trabalho como princípio educativo; (iv) a pesquisa como princípio pedagógico; e, (v) a relação parte-totalidade na proposta curricular.

Sader (2004) ressalta que no século XIX, portanto, partindo da concepção de Marx, afirma-se, pela primeira vez, que o mundo é produto do trabalho humano, como realidade histórica construída coletivamente pelos homens. Também pela primeira vez afirma-se, na filosofia, que o homem é um ser histórico, o que é dado por sua capacidade de trabalho. Assim, reafirma-se a visão ontológica de trabalho do sujeito, que tem como essência fundamental sua interação com a natureza.

O autor destaca que o capital recorre cada vez mais às formas precarizadas e intensificadas de exploração do trabalho, que se torna ainda mais fundamental para a realização de seu ciclo reprodutivo, sendo que o capitalismo necessita desse metabolismo, onde um dos nutrientes principais é a própria alienação. 
Segundo Demo (2018), a dialética problematiza a construção do conhecimento enquanto um processo, uma expressão criativa, que busca desvelar em profundidade o fenômeno não se detendo na aparência, uma vez que o materialismo histórico é compreendido na conjuntura social dos indivíduos, em sua dinamicidade, provisoriedade e transformação e, desse modo, apreende a prática social dos indivíduos em seu convívio social.

\subsection{O princípio educativo sob a ótica de diferentes autores}

Para Soares \& Trindade (2007), o trabalho como princípio educativo norteia os processos de humanização e de atualização histórica do próprio homem, por ser práxis que comporta como um de seus fundamentos, $o$ ato de integrar a ciência, cultura e trabalho, mas ao mesmo tempo, o trabalho na formação histórica do capitalismo impõe limites à emancipação do ser humano.

Assim, o princípio educativo do trabalho, sob a ótica do capitalismo, determinada pelas bases materiais de produção, remete a se pensar na sua dupla face, em que para Soares \& Trindade (2007), a primeira contribui para a educação do trabalhador, em que desta maneira ele tem condição de reconhecer-se no produto de sua obra, aprendendo a se organizar, reivindicar seus direitos, desmistificar ideologias, dominar os conteúdos do trabalho, compreender as relações sociais e a função que nela desempenham.

Já a segunda face, demonstra o trabalho na formação social do capitalismo, ao se instituir como alienação, reforça o sentido da adaptação e impõe limites à emancipação humana. Para fundamentar alguns pressupostos e fazer uma análise sobre a categoria trabalho, buscou-se apoio nos marxistas. E uma das perspectivas que se levanta de antemão para se pensar o trabalho está relacionada a seu sentido ontológico.

Segundo Tumolo (2008), Engels na sua obra "Sobre a transformação do macaco em homem”, enfatiza que o trabalho é a condição básica de toda a vida humana; em suma, foi o trabalho que possibilitou o surgimento do homem. Em que pese todo o limite antropológico desta obra escrita em 1876, o raciocínio desenvolvido é bastante ilustrador e toda a diferença entre o homem e os outros animais encontra-se no trabalho.

A existência humana não é garantida pela natureza, mas tem de ser produzida pelos próprios homens, ou seja, necessitamos aprender a ser homem. Portanto, a produção do homem, e ao mesmo tempo, a formação do homem é um processo educativo. Nas comunidades primitivas, como tudo era comum, não havia a divisão em classes, o processo de educação coincide totalmente com o processo do trabalho. $\mathrm{O}$ advento da propriedade privada e a divisão dos homens em classes sociais distintas provocaram uma divisão também na educação.

A partir desse momento, Saviani (2007) destaca que passamos a ter duas modalidades distintas e separadas de educação: uma voltada para a elite dirigente, geralmente realizada em escolas, centrada nas atividades intelectuais, na oratória e nos exercícios de caráter lúdico ou militar e a outra, para o restante da população, assimilada ao próprio processo do trabalho.

A Revolução Industrial pôs em questão a separação entre instrução e trabalho produtivo, forçando a escola a ligar-se de alguma maneira ao mundo da produção. No entanto, essa educação escolar que a burguesia concebeu, manteve a divisão dos homens em dois grandes grupos: aquele das profissões manuais para os quais se requer uma formação prática limitada à execução de tarefas e aqueles das profissões intelectuais para os quais se requer domínio teórico amplo a fim de preparar as elites.

Essa situação foi percebida pelo importante teórico italiano Antonio Grasmci (2001) ao analisar a situação educacional italiana no início do século XX. Segundo esse autor, verifica-se um processo de progressiva degenerescência: as escolas de tipo profissional, isto é, preocupadas em satisfazer interesses práticos imediatos, predominam sobre a escola formativa, imediatamente desinteressada. 
O aspecto paradoxal reside em que este novo tipo de escola aparece e é louvado como democrático, quando na realidade, não só é destinado a perpetuar as diferenças sociais, como ainda a cristalizá-las em formas chinesas. $\mathrm{O}$ autor defendia uma "escola unitária" no intuito de superar essa dicotomia entre uma educação "desinteressada" propedêutica e humanista de um lado, voltada para os filhos das elites e de formação da classe dirigente, e do outro lado, uma educação mais "interessada", mais prática e manual, voltada para os filhos das camadas populares, para atender as necessidades do mercado de trabalho.

Segundo esse autor, a solução é

[...] uma escola única inicial de cultura geral, humanista, formativa, que equilibre equanimente o desenvolvimento da capacidade de trabalhar manualmente (tecnicamente, industrialmente) e o desenvolvimento das capacidades de trabalho intelectual. Deste tipo de escola única, através de repetidas experiências de orientação profissional, passarse-á a uma das escolas especializadas ou ao trabalho produtivo (Gramsci, 1982, p.118).

Ainda segundo esse autor, todos precisam ter acesso à cultura dominante socialmente construída e apropriada de maneira privada, visto que a educação não pode consistir apenas em que um operário manual se torne qualificado, mas em que cada "cidadão" possa se tornar "governante" e que a sociedade o coloque, ainda que "abstratamente", nas condições gerais de poder fazê-lo; a democracia política tende a fazer coincidir governantes e governados (no sentido de governo com o consentimento dos governados), assegurando a cada governo a aprendizagem gratuita das capacidades e da preparação técnicas gerais necessárias ao fim de governar. (Gramsci, 1982, p.137).

Pensar o trabalho como princípio educativo é resgatar essa perspectiva original de criação do homem através do trabalho. Segundo Marise Ramos (2010) o trabalho como princípio educativo está na base de uma concepção epistemológica e pedagógica, que visa a proporcionar aos sujeitos a compreensão do processo histórico de produção científica, tecnológica e cultural dos grupos sociais, considerada como conhecimentos desenvolvidos e apropriados socialmente, para a transformação das condições naturais da vida e para a ampliação das capacidades, das potencialidades e dos sentidos humanos.

Ao mesmo tempo, Ramos (2010) salienta que é pela apreensão dos conteúdos históricos do trabalho, determinados pelo modo de produção no qual este se realiza, que se pode compreender as relações sociais e, no interior dessas, as condições de exploração do trabalho humano, assim como de sua relação com o modo de ser da educação. Entendemos que para uma ruptura nesse sentido, é necessária uma gestão democrática para que o trabalho como princípio educativo possa ter espaço de atuação e efetivação.

Mota et al. (2021) destaca que para que a gestão democrática se efetive, é importante que toda comunidade escolar seja atuante nos planejamentos, nas decisões e na avaliação no cenário educativo, bem como, a necessidade desta comunidade vivenciar processos participativo, onde irá aprender a ser mais responsável por decisões que englobam não só o espaço escolar, mas se amplia na sociedade. Nesse sentido, esta visão mais ampla de atuação deve englobar o tema sobre o trabalho, principalmente quando vinculado à educação.

E se a sobrevivência do homem não é algo garantido pela natureza, então este tem que procurar produzir os meios de subsistência. Isso nos leva ao entendimento de que o homem verdadeiramente não nasce homem; ele forma-se homem. Eis a compreensão, de acordo com Saviani (2017), de que o trabalho é algo vinculado à aprendizagem; pois no processo de formação do homem através do trabalho, este tanto forma-se homem como exerce o aprendizado na forma de trabalho.

Frigotto (2005) destaca ainda sobre o trabalho como algo educativo e afirma que existe a necessidade de se pensar o trabalho num olhar mais crítico em que o mercado não seja o sujeito, ou seja, a necessidade é por compreender o trabalho em outro contexto social, em que o mercado seja apenas um contexto, e que o homem haja neste cenário produzindo para si mesmo, e não produzindo unicamente para o mercado. Bem como, o produto do trabalho de forma coletiva seja distribuído igualmente. 


\section{Considerações Finais}

Uma vez que o currículo integrado à educação profissional traz em seu cerne o trabalho como um princípio educativo e a indissociabilidade entre o trabalho, a ciência e a cultura, a pesquisa surge como um imperativo para o ser humano alcançar suas necessidades de transformação por meio da ciência, apresentando o cuidado ético e social necessários para tal. Dessa feita, a pesquisa e seus procedimentos teóricos e metodológicos são conceitos a serem vivenciados pelos estudantes em um currículo integrado. Portanto, a produção do homem, e ao mesmo tempo, a formação do homem é um processo educativo.

O mundo do senso comum é o mundo da prática social. E o agir do homem "comum" apresenta-se contraditório, uma vez que tem certa clareza no plano da ação imediata e, ao mesmo tempo, é confuso e inconsequente no plano do pensamento (visão de mundo).

Isso pode ser compreendido como resultado de uma dualidade estrutural decorrente do sistema capitalista, que tem em seu seio a concepção de uma educação simples, mecânica e sem traços intelectuais para as classes menos favorecidas, reservando os postos de trabalhos mais simples e manuais.

Todavia, como consideramos a dialética e as contradições imanentes ao desenvolvimento histórico da sociabilidade humana, há possibilidades de transformações que apontem condições de possibilidade para a construção de um projeto de sociedade mais justo e humano, pensado para além do mercado, tendo como foco o trabalho como princípio educativo como concepção a ser adotada na Educação Profissional e Tecnológica.

Essas considerações aqui situadas são inacabadas e necessitam ser aprofundadas e complementadas por outros trabalhos de pesquisa. Trata-se de um tema fecundo para novas investigações, não só para compreender o trabalho como princípio educativo, mas para possibilitar uma atuação de trabalho mais autônomos, participativo e crítico, capacitados a refletir e produzir novos conhecimentos e transformação social no contexto em que se situam.

\section{Referências}

Araújo, W. \& Siqueira, A. M. (2021) O materialismo histórico dialético e a historicidade da sociedade em Marx (1818-1883). Research, Society and Development, [S. l.], v. 10, n. 2, p. e7410212012, 2021. DOI: 10.33448/rsd-v10i2.12012. Disponível em: https://rsdjournal.org/index.php/rsd/article/view/12012.

Antunes, R. (2007). Os sentidos do trabalho: ensaio sobre a afirmação e negação do trabalho. São Paulo: Boitempo.

Augusto, A. G.; \& Carcanholo, M. D. (2014). Ainda sobre a teoria da história em Marx. In. Lutas Sociais, 18(33),09-22.

Demo, P. (2018). Introdução à metodologia da ciência. São Paulo:

Figueiredo, N. M. A.(2008). Método e metodologia na pesquisa científica. São Caetano do Sul, SP: Yendes Editora.

Frigotto, G., Ciavatta, M., \& Ramos, M. (2005). O trabalho como princípio educativo no projeto de educação integral dos trabalhadores. In: COSTA, Hélio da e CONCEIÇÃO

Gil, A. C. (2008). Métodos e técnicas de pesquisa social (6a ed.). São Paulo: Atlas

Martinho. Educação integral e sistema de reconhecimento e certificação educacional profissional. São Paulo: Secretaria Nacional de Formação - CUT.

Gramsci, A. (1982). Os intelectuais e a organização da cultura. 4. ed. Rio de Janeiro: Civilização Brasileira

Marx, K. (1983) O capital. V. I, tomo 1. São Paulo: Abril Cultural

Mészáros, I. (2008) A educação para além do capital. 2. ed. Tradução de Isa Tavares. São Paulo: Boitempo

Minayo, M. C. S. (org.) Pesquisa social: teoria, método e criatividade. Petrópolis - Rio de Janeiro, Vozes, 1994.

Mota, P. A. T.., Dantas, C. W. M., Fernandes, L. S. L. ., \& Dublante, C. A. S. . (2021). Democratização da gestão escolar: mecanismos de participação na escola. Research, Society and Development, 10(12), e374101220297. https://doi.org/10.33448/rsd-v10i12.20297

Veiga, I. P. A. (2004)As dimensões do processo didático na ação docente. In: ENCONTRO NACIONAL DE DIDÁTICA E PRÁTICA DE ENSINO, 12., 2004, Curitiba, PR,. Anais...Curitiba: Champagnat. v. 1, p.13-30.

Pacheco, E. (Org.). (2012) Perspectivas da Educação Profissional técnica de nível médio. Proposta de Diretrizes Curriculares Nacionais. Secretaria de Educação Profissional e Tecnológica do Ministério da Educação - Setec/Mec. Brasília 
Research, Society and Development, v. 10, n. 15, e73101522614, 2021

(CC BY 4.0) | ISSN 2525-3409 | DOI: http://dx.doi.org/10.33448/rsd-v10i15.22614

Ramos, M. (2019) Implicações políticas e pedagógicas da EJA integrada à educação profissional. Educação e Realidade, Porto Alegre, v. 35 , p. 65-85.

Ramos, M. N. Concepção do Ensino Médio Integrado.2018. https://tecnicadmiwj.files.wordpress.com/2008/09/texto-concepcao-do-ensino- medio-integradomarise-ramos1.pdf>

Saviani, D. (2017). Trabalho e educação: fundamentos ontológicos e históricos. Revista Brasileira de Educação, Campinas, v. 12, n. 32, p. 52-180, jan./abr. 2017.

Saviani, Dermeval. (2003) Pedagogia Histórico-Crítica. 8 ed. Campinas: Autores Associados

Saviani, Dermeval. (2003) Escola e Democracia. 36 ed. Campinas: Autores Associados

Santos, S. M. P. (1997). O lúdico na formação do educador. Petrópolis: Vozes, 1997.

Tumolo, P. S. (2005). O trabalho na forma social do capital e o trabalho como princípio educativo: uma articulação possível? Educ. Soc., Campinas, vol. 26, n. 90, p. $239-265$ 